\title{
Liberação de íons por biomateriais metálicos
}

\author{
Liliane Siqueira de Morais*, Glaucio Serra Guimarães*, Carlos Nelson Elias**
}

\begin{abstract}
Resumo
Objetivo: todo biomaterial metálico implantado possui alguma interação com os tecidos em contato, havendo liberação de íons por dissolução, desgaste ou corrosão. O objetivo deste trabalho foi analisar a liberação de íons metálicos por alguns tipos de biomateriais metálicos, descrevendo a interação íon/tecido e os possíveis efeitos adversos. Conclusão: os tratamentos de jateamento e ataque ácido propiciam aumento na dissolução e liberação de íons metálicos, mas o recobrimento destas superfícies com hidroxiapatita e o polimento eletroquímico reduzem esta tendência de liberação iônica. Na presença de sintomas de reação adversa ao biomaterial deve-se pesquisar sua composição, realizar testes de alergia e optar por materiais não-metálicos ou que não contenham o elemento agressor. As pesquisas sobre liberação de íns devem ser freqüentes, devido ao crescente lançamento de novos biomateriais.
\end{abstract}

Palavras-chave: Liberação de íons. Corrosão. Biomaterial.

\section{INTRODUÇÃO}

Biomaterial é qualquer material sintético que substitui ou restaura a função de tecidos do corpo e que mantém contato contínuo ou intermitente com os fluidos. Considerando que haverá contato com os fluidos, é essencial que o material apresente biocompatibilidade, não produza resposta biológica adversa, não induza efeito sistêmico, não seja tóxico, carcinogênico, antigênico ou mutagênico. Porém, a utilização de biomateriais pode causar efeitos adversos no corpo humano, devido à liberação de íons metálicos citotóxicos ${ }^{1}$. Isto tem atraído o interesse de muitos pesquisadores, pois os produtos de degradação podem induzir reação de corpo estranho ou processo patológico ${ }^{14}$. A liberação de íons metálicos origina-se por dissolu- ção, desgaste ou, principalmente, por corrosão da liga. Sendo assim, a resistência à corrosão é importante na análise da biocompatibilidade.

O objetivo deste trabalho é fazer uma revisão da liberação de íons por diversos tipos de biomateriais metálicos, discutindo sua interação com os tecidos e possíveis efeitos colaterais.

\section{REVISÃO DA LITERATURA}

A maioria dos materiais apresenta algum tipo de interação com o ambiente, o que pode comprometer a utilização do material, devido à deterioração de suas propriedades mecânicas, físicas ou de sua aparência. Um dos processos de degradação é a corrosão. A corrosão é classificada de acordo com a maneira que se manifesta, podendo

* Doutorandos em Ciências dos Materiais - Instituto Militar de Engenharia / University of California, San Diego. Mestre em Ortodontia - Uni-

versidade Federal do Rio de Janeiro.

** Professor do Departamento de Engenharia Mecânica e Ciência dos Materiais - Instituto Militar de Engenharia (IME). 
ser: uniforme, galvânica, em frestas, por pites, intergranular, por lixívia seletiva, erosão-corrosão e corrosão sob tensão ${ }^{4}$.

A corrosão de metais que ocorre na boca é, principalmente, do tipo eletrolítica, devido à interação de duas ligas, que gera corrosão galvânica. Em Ortodontia, a corrosão por pite em braquetes e fios é importante, enquanto a corrosão por fenda ocorre em locais expostos a meios corrosivos (sob ligaduras elastoméricas). Também se observa corrosão devida ao atrito durante o deslizamento do fio metálico no braquete. Somam-se, ainda, flutuações de $\mathrm{pH}$ e temperatura, tensão cíclica, fadiga, flora intrabucal, biofilme, substâncias que entram em contato com as ligas e ácidos da saliva ${ }^{9}$. Desta forma, a corrosão intrabucal é um processo complexo, que depende da composição e estado termomecânico da liga, em combinação com a fabricação, acabamento da superfície, aspectos mecânicos em função, do meio e estado sistêmico do hospedeiro ${ }^{25}$.

\section{Interações entre íons liberados e tecidos}

Os íons liberados pelo processo de corrosão têm o potencial de interagir com os tecidos, por meio de diferentes mecanismos. As reações biológicas acontecem pela interação do íon liberado com uma molécula do hospedeiro, sendo a composição da liga de fundamental importância. Os efeitos causados no organismo aparecem devido à influência do íon sobre os mecanismos de adesão bacteriana, por toxicidade, efeitos subtóxicos ou alergia aos íons metálicos liberados. A adesão bacteriana aumenta com o incremento na energia livre da superfície e com a rugosidade superficial da liga. Reações tóxicas são aquelas que causam danos severos às células e morte celular. A toxicidade das ligas depende da fabricação e pré-tratamento do material, condição da superfície, composição das fases e técnica de fabricação. Reações subtóxicas são aquelas que influenciam a síntese de produtos celulares envolvidos na reação inflamatória. Como exemplo, podem ser citadas as ligas à base de cobre, que induzem os linfócitos a produzirem níveis elevados de IL-2. A alergia pode ser causada como reação adversa a metais como níquel, ouro, paládio, cobalto e outros. O níquel merece especial atenção, devido ao fato das ligas que contêm este elemento serem largamente usadas (aparelhos ortodônticos e próteses). Porém, nem todos os pacientes com teste positivo para níquel irão apresentar reação alérgica. Se os sintomas indicarem possibilidade de alergia, testes alérgicos devem ser feitos ${ }^{25}$.

Os sintomas clínicos de pacientes com efeitos adversos são divididos em queixas subjetivas e sintomas objetivos. Queixas subjetivas são: ardência na boca, gosto metálico e sensações elétricas. Sintomas objetivos aparecem como inflamação gengival, anomalias na língua, descoloração da gengiva, vermelhidão na língua e no palato e lesões brancas ${ }^{25}$.

\section{Liberação de íons por restaurações metálicas}

Ligas metálicas odontológicas que permanecem na cavidade bucal por período de tempo prolongado podem causar efeitos adversos, como conseqüência da corrosão (Fig. 1). Os produtos de corrosão podem acumular nos tecidos bucais e alcançar o trato gastrointestinal, via saliva ${ }^{12}$.

Os produtos de corrosão de ligas odontológicas são encontrados na saliva e na gengiva de pacientes. Normalmente, a quantidade de metal na saliva reflete o teor do metal na restauração. Biópsias de gengivas adjacentes a restaurações metálicas mostram grandes quantidades de meta ${ }^{25}$.

Garhammer et al. ${ }^{11}$ avaliaram a saliva de pacientes com e sem restaurações metálicas e encontraram prata, cromo, cobre, ferro, níquel e zinco nos pacientes com e sem restaurações metálicas, além de ouro, na saliva dos pacientes com restaurações áureas. Os metais encontrados nos pacientes sem restauração indicam que outros fatores afetam o conteúdo de metal na saliva como: nutrição, dieta, fluxo salivar ${ }^{11}$, hormônios, drogas e doenças ${ }^{8}$. 


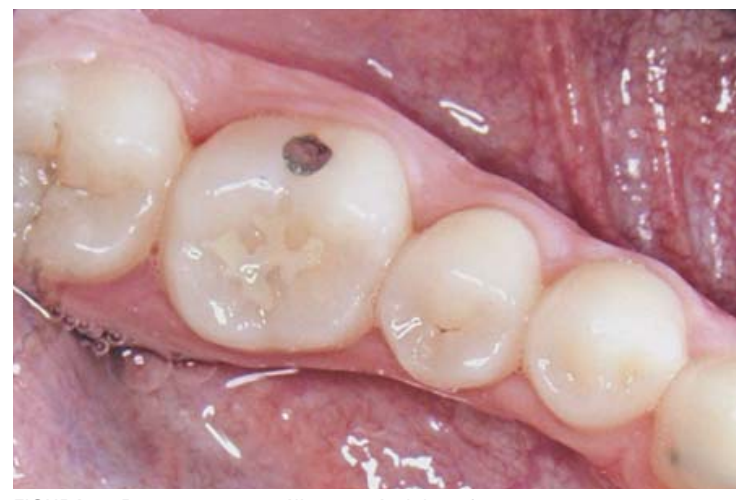

FIGURA 1 - Restauração metálica passível de sofrer corrosão.

\section{Liberação de íons por braquetes e fios ortodônticos}

Existe a preocupação com a liberação de íons (ferro, cromo e níquel) por braquetes de aço inoxidável, mas os fios de Ni-Ti também são fonte de níquel para os pacientes, assim como fios e bandas de aço inoxidável e aparelhos removíveis ${ }^{9}$ (Fig. 2).

O níquel é um nutriente importante na dieta, e está presente em suplementos vitamínicos na dose de $5 \mu \mathrm{g}$ por dia. Apesar da literatura biomédica indicar que o níquel tem efeitos carcinogênicos ${ }^{6}$, mutagênicos ${ }^{18}$ e citotóxicos ${ }^{27}$, a toxicidade documentada, geralmente, se aplica à forma solúvel deste elemento. A sensibilidade ao níquel é a causa mais comum de dermatite alérgica ao metal, mesmo quando este se encontra em pequenas concentrações na liga. Os sinais clínicos mais comuns são inchaço, vermelhidão, formação de vesículas, ulceração, necrose e sensação de ardência na boca ${ }^{7}$.

Eliades et al. ${ }^{9}$ testaram materiais ortodônticos e não encontraram liberação de íons por ligas de níquel-titânio, mas observaram níveis de níquel e cromo liberados por ligas de aço inoxidável. Nenhum dos materiais foi citado como citotóxico, provavelmente devido à baixa quantidade de íns ou pela forma de ligação destes. A ausência de liberação de íons pelas ligas de $\mathrm{Ni}$-Ti pode ser atribuída à camada de óxido de titânio $\left(\mathrm{TiO}_{2}\right)$ com alta densidade, que se forma na superfície da



FIGURA 2 - Aparelho auxiliar com fio de aço inoxidável.

liga. O óxido de titânio é mais estável do que o de cromo, formado na superfície de ligas de aço inoxidável.

A maior liberação de íons por ligas de aço inoxidável tem conseqüências importantes para a rotina clínica, pois além dos braquetes $(2 \mathrm{~g})$, a maioria dos acessórios e aparelhos auxiliares é de aço inoxidável e um tratamento típico inclui pelo menos 8 bandas $(3,6 \mathrm{~g})$ e 2 arcos retangulares $(0,7 \mathrm{~g})$, totalizando $6,3 \mathrm{~g}$ de liga colocada intrabucalmente. A quantidade de íons metálicos liberados por este total de aço inoxidável exposto ao ambiente severo da cavidade bucal pode ser elevada ${ }^{9}$ (Fig. 3).

Materiais não-metálicos, ligas sem níquel e aços com conteúdo reduzido de níquel vêm sendo testados na Ortodontia, assim como a introdução do titânio como material alternativo na produção de braquetes. A razão para a escolha deste material reside em sua biocompatibilidade, ausência de alergenicidade e resistência aumentada à corrosão ${ }^{13}$.

Gioka et al. ${ }^{13}$ investigaram a liberação de íons por braquetes ortodônticos de titânio comercialmente puro e de liga Ti-6Al-4V. O titânio não foi identificado em nenhum dos braquetes, porém, traços de alumínio e vanádio foram encontrados nos braquetes de Ti-6Al-4V, que apresentavam folgas na interface base/aletas. Estas folgas propiciam o acúmulo de placa, criando um meio propício para corrosão em fresta. 


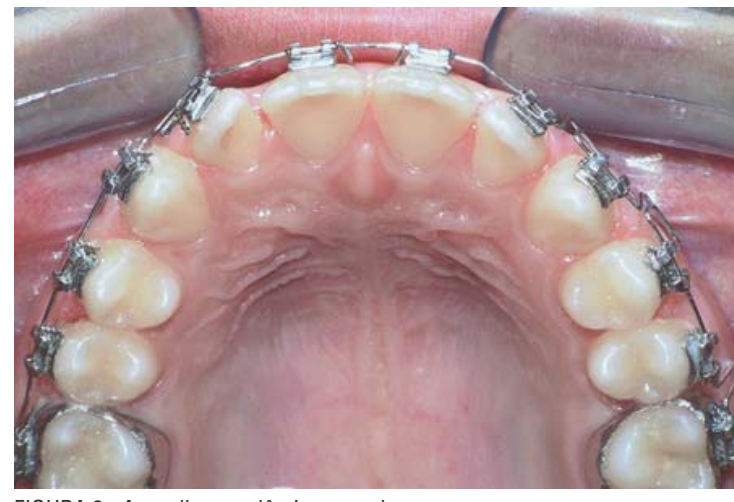

FIGURA 3 - Aparelho ortodôntico completo.

\section{Liberação de íons por implantes metálicos osseointegráveis}

Atualmente, vários sistemas de implantes estão disponíveis, sendo fabricados com biomateriais como titânio comercialmente puro (cp) ou sua liga (Ti-6Al-4V) ${ }^{15}$ (Fig. 4).

A dissolução da liga de titânio deve ser considerada uma fonte de metais que pode ser tóxica. O titânio $\mathrm{cp}$ é mais estável à corrosão ${ }^{16}$ do que as ligas de titânio e por isso é, freqüentemente, usado para implantes ortopédicos.

Os íons liberados pelo processo de degradação e corrosão não permanecem nas proximidades do metal implantado ${ }^{19,26}$. Vasos sanguíneos ou linfáticos, células e fluidos celulares transportam partículas metálicas para tecidos distantes como cérebro, pele, cabelo, unhas e trato gastrointestinal ${ }^{29}$. Elementos metálicos liberados pelo processo de corrosão de implantes bucais foram detectados nos tecidos adjacentes, saliva e tecidos distantes ${ }^{17,29}$. Quantidades variáveis de partículas de titânio foram detectadas em macrófagos, fibrócitos e células gigantes em tecidos adjacentes aos implantes de titânio ${ }^{19,21,24,28}$.

Finet et al. ${ }^{10}$ analisaram a quantidade de titânio liberada por implantes dentários, comparando titânio cp e ligas de titânio, com e sem cobertura de hidroxiapatita. Encontraram titânio em todas as amostras de osso, com a distância de difusão

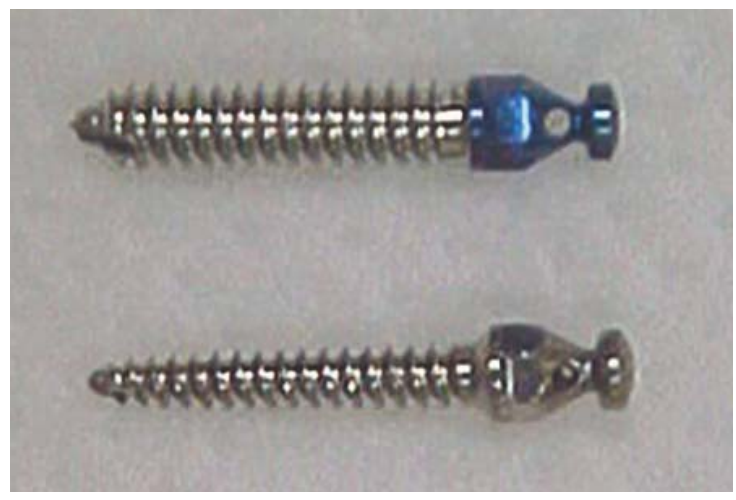

FIGURA 4 - Mini-implantes para ancoragem ortodôntica.

aumentando com o tempo. Encontraram titânio também no fígado, linfonodos e no tecido mole sobre o implante.

O transporte hematógeno pode explicar o acúmulo de metal em órgãos parenquimais como rins e pulmões. Lugowski et al. ${ }^{19}$ encontraram titânio, vanádio e alumínio no cérebro, rim, fígado e baço de coelhos. Schliephake et al. ${ }^{24}$ avaliaram a contaminação por titânio em miniporcos e observaram que os pulmões continham as maiores quantidades de titânio, sendo menor a quantidade nos rins e fígado.

$\mathrm{O}$ acúmulo de metais em alguns tecidos e a difusão destes pelo organismo podem causar desfavoráveis, variando de uma leve descoloração tecidual à osteólise asséptica ou necrose estéril 19,20,24 . Nenhuma reação adversa local ou sistêmica ao titânio foi relatada na literatura. O titânio resiste à corrosão, em parte, devido à formação de um óxido denso $\left(\mathrm{TiO}_{2}\right)$ após exposição ao ar ou eletrólitos aquosos ${ }^{26}$. Por outro lado, $4 \%$ de vanádio e $6 \%$ de alumínio podem ser suficientes para provocar reações adversas sistêmicas e locais ${ }^{26}$. Citotoxicidade, reações teciduais adversas e patologias gerais têm sido associadas ao vanádio e ao alumínio ${ }^{2,22}$. O vanádio pode provocar reações locais ou sistêmicas e inibir a proliferação celular ${ }^{2}$. O alumínio pode estar associado à osteomalácia, granulomatose pulmonar e neurotoxicidade ${ }^{5,22,23}$. 


\section{Liberação de íons por implantes de quadril}

Próteses de quadril necessitam de grande área de interface osso/implante para que a estabilidade seja alcançada o mais breve possível. Esta interface pode ser aumentada pela criação de uma superfície rugosa no implante, por meio de jateamento e ataque ácido da superfície. Porém, a modificação da superfície aumenta a liberação de íons metálicos e de fragmentos, aumentando a taxa de liberação iônica. A fixação inicial pode ser melhorada pela deposição de coberturas bioativas (hidroxiapatita) $)^{3}$.

A liga Ti-6Al-4V tem excelentes propriedades mecânicas para uso em próteses de quadril, mas a liberação de íons metálicos pode causar efeitos carcinogênicos locais e sistêmicos. O titânio e o alumínio podem afetar a função celular, a proliferação celular e a síntese da matriz extracelular. Os íons de titânio, alumínio e vanádio podem inibir a formação de apatita, dificultando a mineralização na interface. A deposição de alumínio tem sido associada também a desordens neurológicas ${ }^{3}$.

De acordo com Browne e Gregson ${ }^{3}$, vários fatores afetam o mecanismo de dissolução do implante (natureza do óxido, condição da superfície e cobertura superficial). $O$ tratamento por envelhecimento reduz a liberação de íons, quando comparado com a passivação com ácido nítrico, pois resulta em óxidos mais resistentes à dissolução. Por outro lado, a hidroxiapatita reduz a liberação de íons em superfícies passivadas com ácido nítrico.

\section{Liberação de íons por piercings metálicos}

Piercings corporais (orelha, língua, nariz, etc) resultam em vários casos de resposta alérgica com inchaço e vermelhidão no local da perfuração, associados à dificuldade de cicatrização da ferida. Azevedo $^{1}$ fez a caracterização de piercings que causaram reações adversas durante o uso e observou que nenhum dos materiais estava de acordo com a norma ISO para materiais metálicos cirúrgicos. Nenhum dos piercings de aço inoxidável passou pelo critério de resistência ao pite e as jóias apresentavam intensas irregularidades na superfície. A menor resistência à corrosão por pite é associada ao acabamento superficial deficiente, o que pode induzir corrosão localizada, promovendo a liberação de íons metálicos citotóxicos e efeitos adversos no corpo humano, incluindo reações alérgicas. Após polimento eletroquímico, as irregularidades superficiais diminuem consideravelmente, indicando que os piercings não foram fornecidos com polimento adequado.

\section{CONCLUSÕES}

A maioria dos biomateriais metálicos libera íns, os quais podem causar efeitos adversos locais ou sistêmicos. Os tratamentos de superfície que visam aumentar a área de contato osso/implante propiciam aumento da dissolução e liberação de íns metálicos. O recobrimento destas superfícies com hidroxiapatita e o polimento eletroquímico reduzem a tendência de liberação de íons.

$\mathrm{Na}$ presença de qualquer sinal ou sintoma de reação adversa a uma liga metálica odontológica, deve-se pesquisar a composição desta, realizar testes de alergia e optar por materiais não-metálicos ou que não contenham o elemento agressor.

A quantidade de metal usada na cavidade bucal é menor que a usada em implantes ortopédicos e induz efeitos menos severos. As pesquisas sobre liberação de íons devem ser freqüentes, devido ao emprego de novos biomateriais metálicos. 


\title{
Ion release from metallic biomaterials
}

\begin{abstract}
Aim: Every metallic biomaterial has some interaction with surrounding tissues, and ion release occurs by dissolution, wearing or corrosion of the alloy. The aim of this paper was to revise the metal ion release from some metallic biomaterials, describing the ion/tissue interaction and the possible side effects. Conclusions: Treatments such as sand blasting and etching increases the amount of metallic ion release, but the surface coated with hydroxyapatite and the polishing decreases the ion release. When clinical signs of side effects to the biomaterial are present one should search its composition, do allergic tests and choose non-metallic biomaterials or biomaterials without the aggressor element. The researches about ion release should be frequent due to the use of new biomaterials.
\end{abstract}

Key words: Ion release. Corrosion. Biomaterials.

\section{REFERÊNCIAS}

1. AZEVEDO, C. R. F. Characterization of metallic piercings. Eng. Failure Anal., [s.l.], v. 10, p. 255-263, 2003.

2. BARCELOUX, D. G. Vanadium. J. Toxicol. Clin. Toxicol., New York, v. 37, p. 265-278, 1999.

3. BROWNE, M.; GREGSON, P. J. Effect of mechanical surface pretreatment on metal ion release. Biomaterials, Oxford, v. 21, p. 385-392, 2000

4. CALLISTER, W. D. Ciência e engenharia de materiais: uma introdução. 5. ed. Rio de Janeiro: LTC, 2002.

5. CHEN, W. J.; MONNAT, R. J. Jr.; CHEN, M.; MOTTET, N. K Aluminum induced pulmonary granulomatosis. Hum. Pathol. Philadelphia, v. 9, p. 705-711, 1978.

6. COSTA, M. Molecular mechanisms of nickel carcinogenesis Toxicol. Appl. Pharmacol., New York, v. 143, p. 152-166, 1997

7. DAHL, B. L. Hypersensitivity to dental materials. In: SMITH, D. C. WILLIAMS, D. F. Biocompatibility of dental materials. 1st. ed. Florida: CRC Press, 1982. Chapter 7.

8. EDGAR, M.; O'MULLANE, D.; DAWES, C. Saliva and oral health 2nd ed. London: British Dental Association, 1996.

9. ELIADES, T.; PRATSINIS, H.; KLETSAS, D.; ELIADES, G.; MAKOU, $M$. Characterization and cytotoxicity of ions released from stainless steel and nickel-titanium orthodontic alloys. Am. J. Orthod. Dentofacial Orthop., St. Louis, v. 125, p. 24-29, 2004

10. FINET, B.; WEBER, G.; CLOOTS, R. Titanium release from dental implants: an in vitro study on sheep. Mater Letters, London, v. 43, p. $159-165,2000$

11. GARHAMMER, P.; HILLER, K. A.; REITINGER, T.; SCHMALZ, G. Metal content of saliva of patients with and without metal restorations. Clin. Oral Investig., Berlin, v. 8, p. 238-242, 2004.

12. GEURTSEN, W. Biocompatibility of dental casting alloys. Crit. Rev. Oral Biol. Med. Alexandria, v. 13, p. 71-84, 2003

13. GIOKA, C.; BOURAUEL, C.; ZINELIS, S.; ELIADES, T.; SILIKAS, N.; ELIADES, G. Titanium orthodontic brackets: structure, composition, hardness and ionic release. Dent. Mater, Kidlington, v. 20, p. 693-700, 2004.

14. HAYES, R. B. The carcinogenicity of metals in humans. Cancer Causes Control., Oxford, v. 8, p. 371-385, 1997

15. JOHANSSON, C. B.; HAN, C. H.; WENNERBERG, A.; ALBREKTS $\mathrm{SON}, \mathrm{T}$. A quantitative comparison of machined commercially pure titanium and titanium-aluminum-vanadium implants in rabbit bone. Int. J. Oral Maxillofac. Implants, Lombard, v. 13, p. 315-321, 1998.

16. KAHN, M. A.; WILLIAMS, R. L.; WILLIAMS, D. F. In-vitro corrosion and wear of titanium alloys in the biological environment. Biomaterials, Oxford, v. 17, p. 2117-2126, 1996

17. KELLER, J. C.; YOUNG, F. A.; HANSEL, B. Systemic effects of porous Ti dental implants. Dent. Mater, Kidlington, v. 1, p. 41-42, 1985
18. LEE, Y. W.; BRODAY, L.; COSTA M. Effects of nickel on DNA methyltransferase activity and genomic DNA methylation levels. Mutat. Res., Amsterdam, v. 415, p. 213-218, 1998

19. LUGOWSKI, S. J.; SMITH, D. C.; McHUGH, A. D.; LOON, V. Release of metal ions from dental implant materials in vivo: determination of $\mathrm{Al}, \mathrm{Co}, \mathrm{Cr}, \mathrm{Mo}, \mathrm{Ni}, \mathrm{V}$ and $\mathrm{Ti}$ in organ tissues. J. Biomed. Mater. Res., Hoboken, v. 25, p. 1443-1458, 1991.

20. MAATA, K.; ARSTILA, A. U. Pulmonary deposits of titanium dioxide in cytologic and lung biopsy specimens. Lab. Invest., Hagerstown, v. 33, p. 342-346, 1975.

21. MALONEY, W. J.; SMITH, R. L.; CASTRO, F.; SCHURMAN, D. J. Fibroblast response to metallic debris in vitro. Enzyme induction cell proliferation and toxicity. J. Bone Joint Surg. Am., Boston, v. 75, p. $835-844,1993$

22. MARQUIS, J. K. Aluminum neurotoxicity: an experimental perspective. Bull. Environ. Contam. Toxicol., New York, v. 29, p. 43-49, 1982

23. PIERIDES, A. M.; EDWARDS Jr., W. G.; CULLUM Jr., U. X.; McCALL, J. T.; ELLIS, H. A. Hemodialysis encephalopathy with osteomalacic fractures and muscle weakness. Kidney Int., New York, v. 18, p. 115-124, July 1980.

24. SCHLIEPHAKE, H.; REISS, G.; URBAN, R.; NEUKAM, F. W.; GUCKEL, S. Metal release from titanium fixtures during placement in the mandible. An experimental study. Int. J. Oral Maxillofac. Implants, Lombard, v. 8, p. 502-511, 1993.

25. SCHMALZ, G.; GARHAMMER, P. Biologic interactions of dental cast alloys with oral tissues. Dent. Mater, v. 18, p. 396-406, 2002.

26. STEINMANN, S. G. Titanium the material of choice? Periodontol. 2000, Copenhagen, v. 17, p. 7-21, 1998.

27. WATAHA, J. C.; SUN, Z. L.; HANKS, C. T.; FANG, D. N. Effect of $\mathrm{Ni}$ ions on expression of intercellular adhesion. J. Biomed. Mater. Res., Hoboken, v. 36, p. 145-151, 1997.

28. WATERS, M. D.; GARDNER, D. E.; COFFIN, D. L. Cytotoxic effects of vanadium on rabbit alveolar macrophages in vitro. Toxicol. Appl. Pharmacol., New York, v. 28, p. 253-263, 1974.

29. WOODMAN, J. L.; JACOBS, J. J.; GALANTE, J. O.; URBAN, R. $M$. Metal ion release from titanium-based prosthetic segmental replacements of long bones in baboons: a long-term study. J. Orthop. Res., Hoboken, v. 1, p. 421-430, 1984.

\section{Endereço para correspondência}

Liliane Siqueira de Morais

Av. Nossa Senhora de Copacabana, 647/1108

CEP: 22.050-000 - Copacabana - Rio de Janeiro/RJ

E-mail: lilianesmorais@hotmail.com 